and isofurans during ischemia/reperfusion of the leg in patients undergoing knee replacement surgery. Free Radic Biol Med. 2011;50:1171-1176.

4. Turan R, Yagmurdur H, Kavutcu M, Dikmen B. Propofol and tourniquet induced ischaemia reperfusion injury in lower extremity operations. Eur J Anaesthesiol. 2007;24:185-189.

5. Saricaoglu F, Dal D, Salman AE, Doral MN, Kilinç K, Aypar U. Ketamine sedation during spinal anesthesia for arthroscopic knee surgery reduced the ischemia-reperfusion injury markers. Anesth Analg. 2005;101:904-909.

6. Yagmurdur H, Ozcan N, Dokumaci F, Kilinc K, Yilmaz F, Basar H. Dexmedetomidine reduces the ischemia-reperfusion injury markers during upper extremity surgery with tourniquet. J Hand Surg Am. 2008;33:941-947.

7. Hand RJr, Riley GP, Nick ML, Shott S, Faut-Callahan M. The analgesic effects of subhypnotic doses of propofol in human volunteers with experimentally induced tourniquet pain. AANA J. 2001;69:466-470.

8. Coulthard P, Rood JP. An investigation of the effect of midazolam on the pain experience. Br J Oral Maxillofac Surg. 1992;30:248-251.

\section{Fat Grafting in Primary Cleft Lip Repair}

Sir:

W e have read with great interest the article entitled "Fat Grafting in Primary Cleft Lip Repair" by Dr. Zellner et al. ${ }^{1}$ In the article, the authors hypothesized that immediate fat grafting during primary cleft lip repair may be of benefit and compared patients who underwent primary cleft lip repair with and without immediate fat grafting.

Final scar analysis revealed statistically significant improvement in scar appearance and contour of the fat-grafted cleft lip repair, concluding that immediate fat grafting may be a promising strategy for improving lip appearance, contour, and scarring during primary cleft lip repair. In cleft lip repair surgery, the goal is a normal-appearing lip and nose, with minimal visible stigmata; however, all surgical repairs leave a cutaneous scar, and unpredictable healing may occur despite the incision pattern chosen and the surgical technique performed.

Many authors have reported how autologous fat grafting could modulate scar formation and enable soft-tissue augmentation. ${ }^{2-4}$ Fat grafting provides softtissue augmentation, enhances contour and structure, and improves skin quality and scar appearance. ${ }^{5}$ Actually, we routinely perform autologous fat grafting to improve the contour of the lip and piriform area in patients who were previously submitted to cleft lip repair, especially in bilateral cases where there is more need for soft-tissue volume, because of the increased tension across the approximated lip flaps that can result in a pronounced scar.

In our experience, autologous fat injection performed several months (at least 6 to 8 months) after primary surgery offers the advantage of allowing recognition, with precision, of the depressed areas that are often not easily recognizable during the first stage. Scarring is a constant and unavoidable aspect of wound healing, and several factors likely contribute to scar quality, including suture type, duration of suture placement, tissue tension, and the child's intrinsic healing capacity.

We never use fat graft injection in primary cleft repair, but we think that the use of intraoperative autologous fat injection should be an excellent procedure, to improve not only the contour but also the cicatrization process, because of the benefits of fat in the first phase of the healing process. In conclusion, we think that the innovation introduced by the authors should be taken into consideration and that injecting at the time of surgery offers a chance to optimize healing of the scar. DOI: $10.1097 /$ PRS.0000000000001665

Francesco Idone, M.D. Jalisco Plastic and Reconstructive Institute University of Guadalajara Guadalajara, Jalisco, Mexico

Andrea Sisti, M.D. Juri Tassinari, M.D.

Giuseppe Nisi, M.D. General and Specialist Surgery Department Plastic Surgery Division University of Siena Siena, Italy

Correspondence to Dr. Idone Jalisco Plastic and Reconstructive Institute University of Guadalajara Avenida Federalismo Norte 2022

Guadalajara, Jalisco, Mexico francescoidone81@hotmail.it

\section{DISCLOSURE}

The authors have no financial interest to declare in relation to the content of this communication. No funding was received for this work.

\section{REFERENGES}

1. Zellner EG, Pfaff MJ, Steinbacher DM. Fat grafting in primary cleft lip repair. Plast Reconstr Surg. 2015;135:1449-1453.

2. Balkin DM, Samra S, Steinbacher DM. Immediate fat grafting in primary cleft lip repair. J Plast Reconstr Aesthet Surg. 2014;67:1644-1650.

3. Duskova M, Kristen M. Augmentation by autologous adipose tissue in cleft lip and nose: Final esthetic touches in clefts. Part I. J Craniofac Surg. 2004;15:478-481; discussion 482.

4. Piccolo NS, Piccolo MS, Piccolo MT. Fat grafting for treatment of burns, burn scars, and other difficult wounds. Clin Plast Surg. 2015;42:263-283.

5. Mazzola RF, Mazzola IC. History of fat grafting: From ram fat to stem cells. Clin Plast Surg. 2015;42:147-153.

\section{Reply: Fat Grafting in Primary Cleft Lip Repair} Sir:

I thank Dr. Idone et al. for their reply and thoughtful comments relating to our article entitled "Fat Grafting in Primary Cleft Lip Repair." Initially, we espoused 